\title{
Large-Scale Crop Production for the Moon and Mars: Current Gaps and Future Perspectives
}

\begin{abstract}
Lucie Poulet ${ }^{1}$, Kenneth Engeling ${ }^{2}$, Tyler Hatch ${ }^{3}$, Sarah Stahl-Rommel ${ }^{4}$, Yo-Ann Velez Justiniano ${ }^{5}$, Sarah Castro-Wallace ${ }^{6}$, Jess Bunchek ${ }^{7}$, Oscar Monje ${ }^{8}$, Mary Hummerick ${ }^{8}$, Christina L. M. Khodadad ${ }^{8}$, LaShelle E. Spencer ${ }^{8}$, Josie Pechous ${ }^{9}$, Christina M. Johnson ${ }^{1}$, Ralph Fritsche ${ }^{10}$, Gioia D. Massa ${ }^{10}$, Matthew W. Romeyn ${ }^{10}$, Aubrie E. O'Rourke ${ }^{10 *}$ and Raymond W. Wheeler ${ }^{10}$

${ }^{1}$ NASA Postdoctoral Program, Universities Space Research Association, Kennedy Space Center, Merritt Island, FL, United States, ${ }^{2}$ Applied Chemistry Laboratories, NASA Kennedy Space Center, Merritt Island, FL, United States, ${ }^{3}$ Low-gravity Exploration Technology Branch, NASA Glenn Research Center, Cleveland, OH, United States, ${ }^{4}$ JES Tech, Houston, TX, United States, ${ }^{5}$ Aerodyne Industries LLC., Marshal Space Flight Center, Huntsville, AL, United States, ${ }^{6}$ Biomedical Research and Environmental Sciences Division, NASA Johnson Space Center, Houston, TX, United States, ${ }^{7}$ Southeastern Universities Research Association, Kennedy Space Center, Merritt Island, FL, United States, ${ }^{8}$ Amentum, Kennedy Space Center, Merritt Island, FL, United States, ${ }^{9}$ Biochemistry, Cell and Molecular Biology, College of Arts and Sciences, Des Moines, IA, United States, ${ }^{10}$ Exploration Research and Technology, NASA Kennedy Space Center, Merritt Island, FL, United States
\end{abstract}

In this perspectives paper, we identify major challenges for space crop production: altered convection in the microgravity environment, scheduling and logistics, crew time and the need for advanced automation, robotics, modeling, and machine learning. We provide an overview of the existing space crop production gaps identified by the Kennedy Space Center (KSC) space crop production team and discuss efforts in current development in NASA projects to address these gaps. We note that this list may not be exhaustive but aims to present the baseline needs for space crop production implementation and a subset of current solutions to the greater scientific community in order to foster further ingenuity.

Keywords: automation, microgreens, plasma agriculture, microbiology, nutrient delivery system, reduced gravity, hydroponic, aeroponics

\section{INTRODUCTION}

As humanity ventures into the Solar System and settles on other planetary bodies, movement towards independence from Earth to produce consumables such as food, oxygen, and water will be crucial. In-situ food production will depend on biological organisms such as plants and to a lesser extent, unicellular organisms. Large-scale crop growth systems included in bioregenerative lifesupport systems (BLSS) will allow for resource recycling and minimize resupplying from Earth. Several projects have aimed to identify the requirements for Lunar and Martian greenhouses, by assessing their feasibility, and developing concepts, theoretical designs, or prototypes at different scales and maturity levels (Wheeler and Martin-Brennan 2000; Stutte et al., 2009; Boscheri et al., 2016; Furfaro et al., 2016; Zeidler et al., 2017). KSC has a long history in controlled environment crop research. This began with the Biomass Production Chamber (BPC), extends to on-orbit platforms such as Veggie and the Advanced Plant Habitat (APH) and will continue with Ohalo III (a crop production chamber currently in development), with each platform deliberately selected and designed to lead to future crop production units destined for the Moon or Mars (Figure 1). 


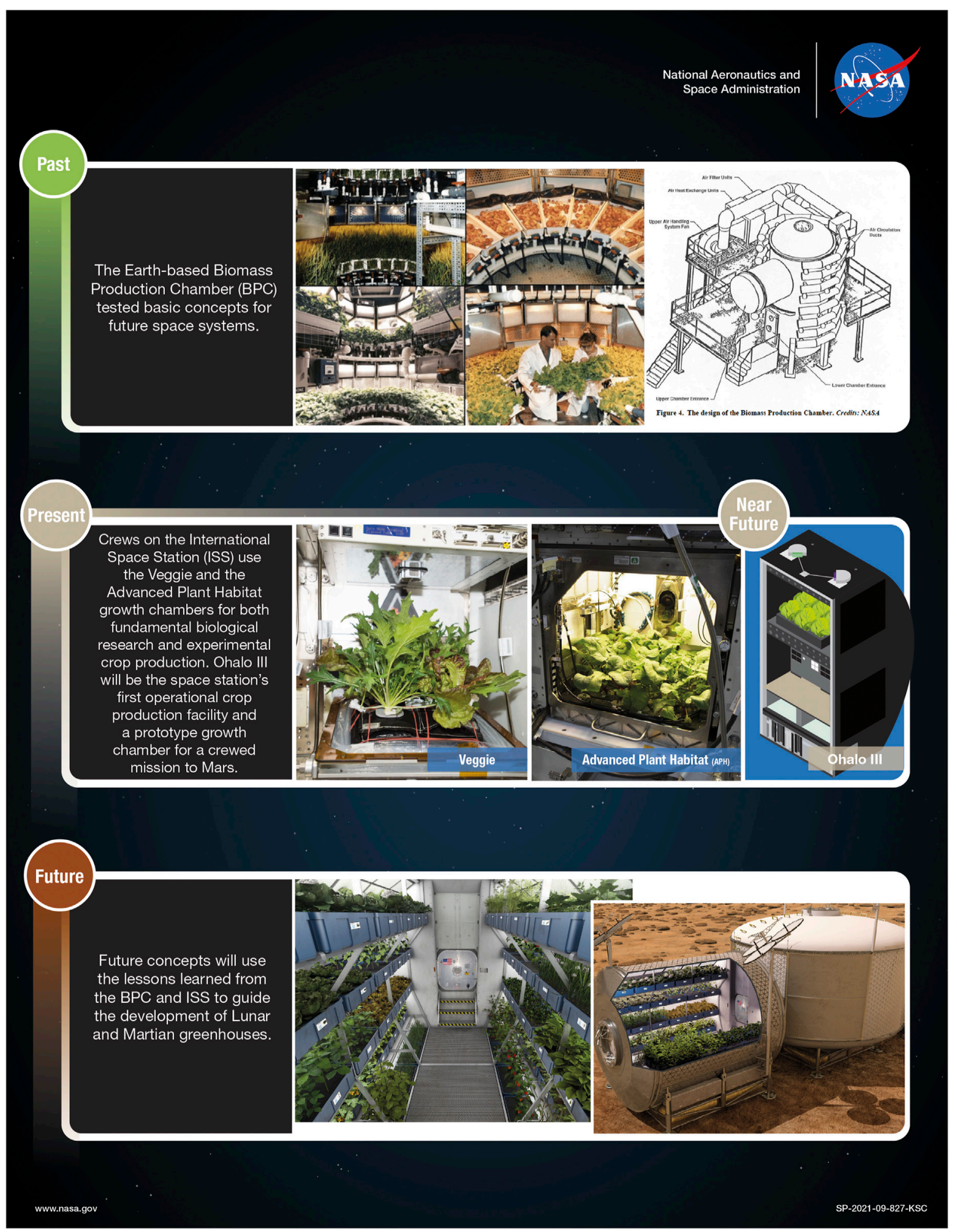

FIGURE1 | Examples of KSC's prior, current and future space crop production platforms selected and designed to lead to crop production units destined for the Moon or Mars. 
Larger-scale platforms will bring new engineering challenges and needs. A set of logistical and physical obstacles have been identified as informed by the lessons learned from KSC's space crop production efforts on the International Space Station (ISS) using small scale platforms.

\section{SPACE CROP PRODUCTION GAPS AND NEEDS}

Space crop production efforts utilize the lessons learned from growing plants on the ground and in orbit. This knowledge, in combination with the expertise across NASA centers, academia, and industry serves to provide a framework for crop production systems for deep space travel (Johnson et al., 2021). Prior work conducted in plant chambers aboard the Shuttle and ISS has helped identify knowledge gaps and technology needs for space crop production (Supplementary Table S1). Throughout the remainder of this perspectives paper, we present a sampling of the current technologies being explored at NASA centers to address specific gaps, and we discuss their associated limitations and challenges.

\subsection{Water and Nutrient Delivery: Challenges, Needs, and Current Research}

Plant testing on the Shuttle and ISS revealed challenges with water and nutrient delivery. The lack (or reduction) of buoyancy-driven convection and the domination of surface-tension forces in reduced gravity leads to thick boundary layers of water (respectively air) forming around plant roots (respectively leaves) (Kitaya et al., 2003; Jones et al., 2012). Without appropriate water and nutrient delivery systems, roots suffer from hypoxia. Although substrate-based watering systems using capillary forces to guide water to the roots without suffocating them, are currently used on the ISS (e.g. Veggie and Advanced Plant Habitat (APH)) (Zabel et al., 2016), substrate-free or reduced-substrate water and nutrient delivery systems are being considered for future missions to reduce upmass and waste (Morrow et al., 2017). We present recent work investigating spaceflight testing of a hydroponics system and an Earth-based analog demonstration of aeroponics.

\subsubsection{Substrate-Less Growth Systems}

Space crop production efforts to date have focused on substratebased approaches mainly using arcillite for plant growth, for proof of concept demonstration of crop growth (Massa et al., 2018). The approach is similar to terrestrial methods, yet as discussed above, watering proves a challenge in the microgravity. Among water solutions for substrate-based growth methods is a passive watering system named Passive Orbital Nutrient Delivery System (PONDS) where plants will draw from a free-standing reservoir of water (Levine et al., 2021). Recently, NASA has tested on-orbit a substrate-less hydroponics approach known as Plant Water Management (PWM). The PWM uses capillary geometry to contain poorly wetting aqueous solutions (e.g., sugary or nutrient-rich water), and provide sufficient aeration and hydration for low-g hydroponics (Mungin et al., 2019). Initial low-g data analysis showed that this could be a viable method, and further testing will include the use of space crops rather than the current simulated plants.

Furthermore, KSC's ongoing collaborative work with the German Aerospace Center (DLR) Institute of Space Systems in the analog extreme environmental setting of the EDEN ISS greenhouse facility at the Neumayer Station III site in Antarctica, has provided precedence for using an aeroponics approach (Zabel et al., 2017). Aeroponic nutrient delivery and a modified ebb/flow technique for plant growth systems in microgravity will also be evaluated using the eXposed Root On-Orbit Test System (XROOTS) (Morrow et al., 2017). In addition, the Porous Tube Nutrient Delivery System (PTNDS), which utilizes suction to hold plants seeded onto a porous ceramic water delivery tube, is in current development with additional watring approaches under development by university and industry researchers (Monje et al., 2019).

\subsubsection{Fertilizer/Nutrient Supply: Plasma Activation of Water}

In the realm of nutrient delivery, a recent and interesting development in plasma agriculture (use of plasma, the fourth state of matter, to generate reactive species that interact chemically) is the plasma activation of water (PAW). For $\mathrm{PAW}$, the introduction of plasma to water is able to change its properties (Foster et al., 2018). Plasma research is underway at KSC to explore the use of low temperature plasma to treat water, serve as a microbial sanitization method for hardware, and to explore plasma introduction of NOx groups and changes in $\mathrm{pH}$ for fertilizer-like applications. There is yet to be a complete understanding of plasma water chemistry, with prior and ongoing research at UC-Berkeley (Graves 2012) and recent modeling efforts at the University of Michigan (Kruszelnicki et al., 2019).

\subsection{Crop Cultivation: Challenges, Needs, and Current Research at KSC}

Volume is a limited resource in space, and future crop production systems will need to use available growth space effectively. In microgravity, plants can grow in all dimensions, thus making use of the entire available volume. Trade-off studies between monocrop and multicrop cultivation will help to determine if growth units will benefit from one or multiple crop species (Boscheri et al., 2016; Zeidler et al., 2017). To use volume efficiently, crop scheduling is also key. Depending on the growth cycles of individual species, crop planting could be staggered to meet dietary needs of the crew (Zeidler et al., 2017).

Together, NASA and the United States Department of Agriculture (USDA) are investigating the use of microgreens, plants that are small in size, nutrient-dense, and quick to grow with little crew time. Ready-to-eat plants like microgreens are easy to maintain and the rich nutrient and phytochemical composition of microgreens can help mitigate spaceflightinduced health risks (Anderson et al., 2017; Cooper et al., 2017). Microgreens have a high-volume optimization potential, 
and efficiently use light, fertilizer, and water, all of which are important selection criteria for plants grown in space (Romeyn et al., 2019). These crops are harvested one to 3 weeks after planting, when the cotyledons are fully expanded, and the first true leaves have emerged (Xiao et al., 2012; Xiao et al., 2016). The short growth cycle of microgreens adds flexibility to crop systems, especially if disruptions occur. Microgreen production would require more seeds than full size crop production, but seeds are small and light, and the mass of seeds is largely offset by the reduced mass of fertilizer and their small volume requirements. An upcoming project at KSC will work to quantify this trade-off.

\subsection{Environmental Monitoring Platform: Stress Detection and Food Safety Technologies}

Studying plant growth in simulated and actual space flight environments, will enable the development of plant growth mechanistic and knowledge models. Such models can account for the combined physical, biochemical, and morphological phenomena involved; a necessary tool to accurately control and predict plant growth in life-support systems (Hézard et al., 2010; Poulet et al., 2020). In addition, we aim to achieve an advanced level of autonomy by implementing an integrated machine learning approach to monitor and coordinate space crop production systems, including the plant compartment atmospheric conditions, plant and microbiome genomic and metabolomic trends, water system microbiome and chemistry, and biomass recycling. Crew time for crop cultivation in future missions will be limited, as the primary activity of astronauts will be to accomplish mission tasks (Russell et al., 2006). Future space crop systems will need to be less crew time-intensive than current systems (Poulet et al., 2021; Zeidler et al., 2021) and utilize automation (e.g., watering or health monitoring). Small space crop production chambers on ISS, such as Veggie and the APH, can be used to validate and inform automation efforts, such as disease detection by imaging.

\subsubsection{Hyperspectral Imaging}

Monitoring plant growth and health during the entire life cycle of a crop is needed to ensure food safety of crops eaten by astronauts during cis-lunar, lunar and Martian missions (Anderson et al., 2017; Monje et al., 2019). Hyperspectral imaging can collect relevant spectral data for developing suitable vegetation indices, providing non-destructive and autonomous estimates of plant health with minimal crew time (Gowen et al., 2007; Araus and Cairns 2014; Huang et al., 2018; Zeidler et al., 2019). Early identification of plant responses to nutrient deficiencies, drought, flooding, or microbial/fungal infections, will provide the crew with enough time to mitigate these problems (Kim et al., 2001; Gowen et al., 2007). To this end, a prototype Plant Health Monitoring (PHM) system was developed by the USDA Environmental Microbial and Food Safety Laboratory (EMFSL, Beltsville, MD) and is in operation at KSC (Monje et al., 2021). The PHM is being used to develop a database of images from plants exposed to abiotic (e.g. drought) or biotic (e.g. fungal infection) stresses. This database will be used to develop suitable vegetation indices for autonomous early stress detection and for training future AI algorithms for plant health monitoring and to ensure food safety. In the future, miniature imaging systems will be deployed for monitoring plant health and microbial composition remotely in spacecraft such as ISS, Gateway, and Deep Space Transport.

\subsubsection{Microbial Sequencing}

Molecular methods have been essential for understanding plantassociated microbiomes (Bulgarelli et al., 2012; Chaparro et al., 2014; Knief 2014) and plant pathogens (Pecman et al., 2017; DíazCruz et al., 2019; Piombo et al., 2021). Monitoring the microbes present in the spaceflight environment has been important since Apollo, but with short mission durations, not practical to perform during flight. For the ISS, requirements were generated to ensure that microbial contamination was periodically assessed in the ISS air, water, and on surfaces (Castro et al., 2004; Yamaguchi et al., 2014). From the beginning of plant growth on ISS, plants and plant growth hardware have been routinely sampled to understand the plant microbiome interaction and pathogen control in supplemental food production (Hummerick et al., 2010, Hummerick et al., 2011, Hummerick et al., 2012; Massa et al., 2017b; Khodadad et al., 2020). Veggie plant samples have been evaluated by culture-based isolation and identification, as well as microbiome analysis using Next Generation Sequencing on the Illumina MiSeq platform upon return to Earth (Khodadad et al., 2020). Such assessments of the microbiological food safety of crops grown on orbit has led to the development of a hazard analysis critical control point plan (HACCP) for space crop cultivation (Hummerick et al., 2011; 2012). The goal for spaceflight microbiology is to move beyond the need to culture potentially harmful microorganisms and to this end, culture-independent, swab-to-sequencer processes using the Oxford Nanopore MinION are now conducted onboard the ISS (Stahl-Rommel et al., 2021).

Future paths to assess plant-microbe interactions in the space crop production environment can benefit from the development of system level approaches where the power of automated sensing through imaging, omics (genomics, transcriptomics) and spectrometry (metabolomics, nutrients, volatiles) is realized. This surveillance, in combination with correlative and machine learning techniques, will allow for the detection of stress indicators, plant and human pathogens, reduced nutrient content, or the formation of health-hazardous volatiles, respectively.

\subsection{Microbiome Ecosystem-Related Needs 2.4.1 Microbial Control Solutions for Watering Systems}

Microbial biofilms have been a cause for concern in ISS biodeterioration, and as such, represent a risk to safe longterm human space exploration (Landry et al., 2020). Research into the effects of spaceflight on microbes has unveiled changes in virulence and biofilm formation under microgravity conditions (Kim et al., 2013), further underlining the need to develop robust biofilm management solutions (Landry et al., 2020). NASA continues to explore treatment methods such as biocides, 
antimicrobial surfaces, nutrient filters, applied shockwaves, thermal and UV treatments (Velez-Justiniano et al., 2020). Biofilm management studies explore the use of other biological agents (such as bacteriophages or plasmids) to balance the ISS Water Processor Assembly (WPA) ecosystem (Sillankorva and Azeredo 2014) and even consider plasma-based approaches. The identification of the best solution for microbial control can be tailored to the relevant platform, be this a space crop production chamber, or the water processing system used for downstream irrigation.

\subsubsection{Plasma for Seed Sanitization}

To avoid contamination by plant or human pathogens in space crop production platforms, seed surface sanitization is carried out before flight. Traditional methods of seed sanitization on the ground include alcohol soaking and chemical gas fumigation (Khamsen et al., 2016; Massa et al., 2017a), but these methods are not effective for all seeds. Plasma treatment of seeds, surfaces, or containers inoculated with fungi or bacteria have demonstrated significant log reductions after exposure (Filatova et al., 2009; Takemura et al., 2014; Puligundla et al., 2017a, Puligundla et al., 2017b; Zahoranová et al., 2018). The effectiveness of seed or surface sanitation may vary greatly based upon the plasma source and plasma gaseous medium being employed. Preliminary work is being conducted at KSC to test space crop production seed sanitization using different plasma sources and their effects on the associated seed microbiome.

\section{DISCUSSION}

\subsection{Hyperspectral Imaging Current Challenges and Prospects}

Although hyperspectral imaging enables precision plant health monitoring and early detection of diseases, it is currently limited by several factors. Data collection and analysis is dependent on the conditions in which measurements were performed, such as leaf orientation, illumination, or even leaf texture (Mahlein, 2016; Zeidler et al., 2019). Currently, spectral vegetation indices (SVI) are tied to specific wavelengths and obtained with specific environmental conditions and plant species, which means data to define SVI need to be collected in a high-fidelity environment. It is hard to apply SVIs to different conditions and plant types without risking data misinterpretation (Lowe et al., 2017; Thomas et al., 2018). The amount of data produced is large and therefore requires the development of efficient data handling and analysis methods (Mahlein, 2016; Thomas et al., 2018). For space applications, this raises the issue of telemetry limitations, which translates into the need for in situ processing. However, deep learning algorithms seem to be a promising solution for hyperspectral data analysis and interpretation (Thomas et al., 2018; Nagasubramanian et al., 2019), provided that they can be trained on a big enough dataset (Zeidler et al., 2019).

\subsection{Substrate-Free vs. Substrate-Based}

Alongside substrate-less systems presented in section 2.3.1, substrate-based systems using lunar or Martian regolith are being investigated (Wamelink et al., 2019; Eglin and Guinan, 2020; Eichler et al., 2021; Fackrell et al., 2021). Plant growth experiments have been conducted with returned Moon material (Ferl and Paul, 2010) and Wamelink et al. (2019) have successfully grown nine different species in JSC-1A regolith simulant mixed with organic material and further projects, such as the Mars Gardens, have compared this regolith simulant approach to hydroponic growth methods (Eglin and Guinan, 2020). Among the concerns raised when cultivating plants in regolith was the fact that it cannot be used as is; harmful compounds (e.g., perchlorates) need to be removed from Martian regolith and organic materials need to be added (Eichler et al., 2021). Furthermore, geomicrobiological methods have the potential to modify regolith to enable its utilization for plant growth. In this scenario, microorganisms are used to create soil from Lunar and Martian regolith (Verseux et al., 2016). Previous studies on plant growth in regolith simulants may have overlooked some important chemical composition aspects. However, the recent development of agriculturally relevant Martian regolith will enable more accurate studies (Fackrell et al., 2021). For the near term, hydroponic systems may prove a better option that is more amenable to a BLSS infrastructure. Hydroponic systems provide efficient absorption of nutrients as roots are directly in contact with the nutrient solution (Eglin and Guinan, 2020) and easy monitoring for subsequent control of the root zone microbiome.

\subsection{Plasma Technology Development and Cost Reduction}

Plasma applications in agriculture have largely focused on 1) plasma activated water, 2) seed germination, growth, and development, and 3) seed sanitization and biofilm sanitation. Uunderstanding of the chemistry and uses of plasma activated water is far from complete, but there are potential benefits in terrestrial and off-Earth controlled environment agriculture (Besten, 2019; Ranieri et al., 2020). As resupply is costly, plasma based applications and technologies provide an avenue of investigation worth researching to reduce the reliance on conventional methods of sanitation. The plasma source and gas requirements can be small, potentially even using breathable air. On Earth, use of plasma activated water is not widespread due to the problem of scaling for industrial use. Plasmas can be expensive outside of a laboratory setting and conventional methods are cheaper and within regulatory requirements. As advancements in electronics are rapidly decreasing costs, and regulations become stricter on particulate contaminants, plasma becomes a more favorable option. Additionally, new research is providing insight into plasma interactions with water and plasmawater chemistry that allow for system optimization of tasks. Although the application of plasma in various water systems is in its infancy, it should be considered as an aid or potential replacement to some current methodologies. 


\section{CONCLUDING REMARKS}

As NASA and its commercial partners are getting closer to Gateway and robotic and crewed lunar surface missions, it is imperative to plan for large-scale crop production systems that will be deployed on the Moon and Mars. These present numerous challenges, and significant technology development and knowledge gaps need to be resolved prior to successful implementation. We have presented select considerations currently under investigation at NASA centers that can be integrated into large-scale crop production systems design to address these gaps. While not exhaustive, these state-of-the-art technologies include new methods for space crop production, environmental monitoring, water processing, and microbial containment approaches. Future crop production systems must be resilient, but also evolvable, so that new advances can be implemented as innovations occur. It will require contributions from numerous disparate disciplines to feed future exploration.

\section{DATA AVAILABILITY STATEMENT}

The original contributions presented in the study are included in the article/Supplementary Material, further inquiries can be directed to the corresponding author.

\section{REFERENCES}

Anderson, M. S., Ewert, M. K., and Keener, J. F. (2018). Life Support Baseline Values and Assumptions Document. NASA. https://ntrs.nasa.gov/archive/nasa/casi. ntrs.nasa.gov/20180001338.pdf.

Anderson, M. S., Barta, D., Douglas, G., Motil, B., Massa, G., Fritsche, R., et al. (2017). "Key Gaps for Enabling Plant Growth in Future Missions," in AIAA Space Forum. AIAA SPACE and Astronautics Forum and Exposition (American Institute of Aeronautics and Astronautics). doi:10.2514/6.2017-5142

Araus, J. L., and Cairns, J. E. (2014). Field High-Throughput Phenotyping: The New Crop Breeding Frontier. Trends Plant Sci. 19 (1), 52-61. doi:10.1016/ j.tplants.2013.09.008

Arena, C., De Micco, V., Macaeva, E., and Quintens, R. (2014). Space Radiation Effects on Plant and Mammalian Cells. Acta Astronautica 104 (1), 419-431. doi:10.1016/j.actaastro.2014.05.005

Bates, S., Gushin, V., Bingham, G., Vinokhodova, A., Marquit, J., and Sychev, V. (2009). Plants as Countermeasures: A Review of the Literature and Application to Habitation Systems for Humans Living in Isolated or Extreme Environments. Habitation 12 (1), 33-40. doi:10.3727/154296610X12686999887201

Batten, J. H., Stutte, G. W., and Wheeler, R. M. (1995). Effect of Crop Development on Biogenic Emissions from Plant Populations Grown in Closed Plant Growth Chambers. Phytochemistry 39 (6), 1351-1357. doi:10.1016/0031-9422(95) 00126-R

Batten, J. H., Stutte, G. W., and Wheeler, R. M. (1996). Volatile Organic Compounds Detected in the Atmosphere of NASA's Biomass Production Chamber. Adv. Space Res. 18 (4), 189-192. doi:10.1016/0273-1177(95) 00876-G

Besten, J. d. (2019). "Chapter 8.2 - Vertical Farming Development; the Dutch Approach," in Plant Factory Using Artificial Light. Editors M. Anpo, H. Fukuda, and T. Wada (Elsevier), 307-317. doi:10.1016/B978-0-12-813973-8.00027-0

Bingham, G. E., Levinskikh, M. A., Sytchev, V. N., and Podolsky, I. G. (2000). Effects of Gravity on Plant Growth. J. Gravit. Physiol. 7 (2), P5-P8.

Boscheri, G., Lamantea, M., Lobascio, C., and Paille, C. (2016). "The MELiSSA GreenMOSS Preliminary Design Study: A Greenhouse Module on the Lunar

\section{AUTHOR CONTRIBUTIONS}

LP, KE, TH, SS-R, Y-AV, SC-W, JB, OM, MH, CK, JS, MR, and GM contributed by writing the paper. All authors edited and revised the paper. AO coordinated the effort. GM and RW oversaw this coordination.

\section{FUNDING}

Funding provided in part by NASA Biological and Physical Sciences Program.

\section{ACKNOWLEDGMENTS}

We would like to acknowledge the hard work and dedication of all researchers and engineers who make Space Crop Production work possible at NASA centers.

\section{SUPPLEMENTARY MATERIAL}

The Supplementary Material for this article can be found online at: https://www.frontiersin.org/articles/10.3389/fspas.2021.733944/ full\#supplementary-material

Surface," in 46th International Conference on Environmental Systems. International Conference on Environmental Systems (ICES), Vienna, Austria, July 10-14, 2016 (American Institute of Aeronautics and Astronautics).

Brown, A. H., Chapman, D. K., Anders, J., and Heathcote, D. (1995). Gravitropic Responses of the Avena Coleoptile in Space and on Clinostats. I. Gravitropic Response Thresholds. Physiologia Plantarum 95 (1), 27-33. doi:10.1111/j.13993054.1995.tb00803.x

Bücker, H., and Horneck, G. (1975). The Biological Effectiveness of HZE-Particles of Cosmic Radiation Studied in the Apollo 16 and 17 Biostack Experiments. Acta Astronautica 2 (3), 247-264. doi:10.1016/0094-5765(75)90095-8

Bulgarelli, D., Rott, M., Schlaeppi, K., van Themaat, E. V. L., Ahmadinejad, N., Assenza, F., et al. (2012). Revealing Structure and Assembly Cues for Arabidopsis Root-Inhabiting Bacterial Microbiota. Nature 488 (7409), 91-95. doi:10.1038/nature11336

Campbell, W. F., Salisbury, F. B., Bugbee, B., Klassen, S., Naegle, E., Strickland, D. T., et al. (2001). Comparative Floral Development of Mir-Grown and EthyleneTreated, Earth-Grown Super Dwarf Wheat. J. Plant Physiol. 158 (8), 1051-1060. doi:10.1078/S0176-1617(04)70129-7

Carter, L., Williamson, J., Gazda, D., Brown, C., Ryan, S., Frank, T., et al. (2019). Status of ISS Water Management and Recovery. Boston, Massachusetts. Available at: https://ttu-ir.tdl.org/handle/2346/84720.

Castro, V. A., Thrasher, A. N., Healy, M., Ott, C. M., and Pierson, D. L. (2004). Microbial Characterization during the Early Habitation of the International Space Station. Microb. Ecol. 47 (2), 119-126. doi:10.1007/s00248-003-1030-y

Chaparro, J. M., Badri, D. V., and Vivanco, J. M. (2014). Rhizosphere Microbiome Assemblage Is Affected by Plant Development. ISME J. 8 (4), 790-803. doi:10.1038/ismej.2013.196

Cooper, M., Perchonok, M., and Douglas, G. L. (2017). Initial Assessment of the Nutritional Quality of the Space Food System over Three Years of Ambient Storage. Npj Microgravity 3 (1), 1-4. doi:10.1038/s41526-017-0022-z

Corey, K. A., Barta, D. J., and Wheeler, R. M. (2002). Toward Martian Agriculture: Responses of Plants to Hypobaria. Life Support Biosph. Sci. 8 (2), 103-114.

Croxdale, J., Cook, M., Tibbitts, T. W., Brown, C. S., and Wheeler, R. M. (1997) Structure of Potato Tubers Formed during Spaceflight. J. Exp. Bot. 48 (12), 2037-2043. doi:10.1093/jxb/48.12.2037 
De Micco, V., Arena, C., Pignalosa, D., and Durante, M. (2011). Effects of Sparsely and Densely Ionizing Radiation on Plants. Radiat. Environ. Biophys. 50 (1), 1-19. doi:10.1007/s00411-010-0343-8

Díaz-Cruz, G. A., Smith, C. M., Wiebe, K. F., Villanueva, S. M., Klonowski, A. R., and Cassone, B. J. (2019). Applications of Next-Generation Sequencing for Large-Scale Pathogen Diagnoses in Soybean. Plant Dis. 103 (6), 1075-1083. doi:10.1094/PDIS-05-18-0905-RE

Donà, M., and Mittelsten Scheid, O. (2015). DNA Damage Repair in the Context of Plant Chromatin. Plant Physiol. 168 (4), 1206-1218. doi:10.1104/pp.15.00538

Eglin, A., and Guinan, E. (2020). "The Mars Gardens: a Comparison of the Viability of Plants Grown in Martian Simulant Regolith and in a Hydroponics System," in American Astronomical Society Meeting, Honolulu, Hawaii, January 4-8, 2020.

Eichler, A., Hadland, N., Pickett, D., Masaitis, D., Handy, D., Perez, A., et al. (2021). Challenging the Agricultural Viability of Martian Regolith Simulants. Icarus 354, 114022. doi:10.1016/j.icarus.2020.114022

Fackrell, L. E., Schroeder, P. A., Thompson, A., Stockstill-Cahill, K., and Hibbitts, C. A. (2021). Development of Martian Regolith and Bedrock Simulants: Potential and Limitations of Martian Regolith as an In-Situ Resource. Icarus 354, 114055. ISSN 0019-1035. doi:10.1016/j.icarus.2020.114055

Ferl, R., and Paul, A. L. (2010). Lunar Plant Biology-A Review of the Apollo Era. Astrobiology 10, 261-274. doi:10.1089/ast.2009.0417

Ferl, R., Wheeler, R. M., Levine, H. G., and Paul, A. L. (2002). Plants in Space. Curr. Opin. Plant Biol. 5 (3), 258-263. doi:10.1016/s1369-5266(02)00254-6

Filatova, I., Azharonok, V., Gorodetskaya, E., nikova, L., Shedikova, O., and Shik, A. (2009). "Plasma-Radiowave Stimulation of Plant Seeds Germination and Inactivation of Pathogenic Microorganisms," in Proceedings of the International Plasma Chemistry Society.19January

Foster, J. E., Mujovic, S., Joseph, G., and Blankson, I. M. (2018). Towards High Throughput Plasma Based Water Purifiers: Design Considerations and the Pathway towards Practical Application. J. Phys. D: Appl. Phys. 51 (29), 293001. doi:10.1088/1361-6463/aac816

Furfaro, R., Sadler, P., and Giacomelli, G. A. (2016). "Mars-lunar Greenhouse (M-LGH) Prototype for Bioregenerative Life Support Systems in Future Planetary Outposts," in 67th International Astronautical Congress. International Astronautical Congress (IAC), Guadalajara, Mexico, September 26-30, 2016 (International Astronautical Federation, IAF).

Gowen, A. A., O’Donnell, C. P., Cullen, P. J., Downey, G., and Frias, J. M. (2007). Hyperspectral Imaging - an Emerging Process Analytical Tool for Food Quality and Safety Control. Trends Food Sci. Techn. 18 (12), 590-598. doi:10.1016/ j.tifs.2007.06.001

Graves, D. B. (2012). The Emerging Role of Reactive Oxygen and Nitrogen Species in Redox Biology and Some Implications for Plasma Applications to Medicine and Biology. J. Phys. D: Appl. Phys. 45 (26), 263001. doi:10.1088/0022-3727/45/ $26 / 263001$

Hawkes, C. V., and Connor., E. W. (2017). Translating Phytobiomes from Theory to Practice: Ecological and Evolutionary Considerations. Phytobiomes J. 1 (2), 57-69. doi:10.1094/PBIOMES-05-17-0019-RVW

He, C., Davies, F. T., and Lacey, R. E. (2007). Separating the Effects of Hypobaria and Hypoxia on Lettuce: Growth and Gas Exchange. Physiologia Plantarum 131 (2), 226-240. doi:10.1111/j.1399-3054.2007.00946.x

Hézard, P., Sasidharan, S., Cruely, C., and Dussap, C-G. (2010). "Higher Plants Modeling for Bioregenerative Life Support Applications: General Structure of Modeling," in 40th International Conference on Environmental Systems. International Conference on Environmental Systems (ICES), Barcelona, Spain, July 11-15, 2010 (American Institute of Aeronautics and Astronautics). doi:10.2514/6.2010-6079

Hintze, P., Franco, C., Hummerick, M., Maloney, P., and Spencer, L. (2017). Evaluation of Low-Pressure Cold Plasma for Disinfection of ISS Grown Produce and Metallic Instrumentation. Available at: https://tu-ir.tdl.org/handle/2346/ 73000 .

Hoehn, A., Paul, S., Stodieck, L., James, C., Kalinowski, W., Rakow, A., et al. (2000). Microgravity Root Zone Hydration Systems. SAE Tech. Pap. August, 776-5760. doi:10.4271/2000-01-2510

Huang, P., Luo, X., Jin, J., Wang, L., Zhang, L., Liu, J., et al. (2018). Improving HighThroughput Phenotyping Using Fusion of Close-Range Hyperspectral Camera and Low-Cost Depth Sensor. Sensors 18 (8), 2711. doi:10.3390/s18082711

Hummerick, M., Garland, J., Bingham, G., Wheeler, R. M., Topham, S., Sychev, V., et al. (2011). "A Hazard Analysis Critical Control Point Plan Applied to the Lada Vegetable Production Units (VPU) to Ensure the Safety of Space Grown Vegetables," in 41st International Conference on Environmental Systems, Portland, Oregon, July 17-21, 2011 (American Institute of Aeronautics and Astronautics). doi:10.2514/6.2011-5277

Hummerick, M., Gates, J., Nguyen, B. T., Massa, G., and Wheeler, R. M. (2012). "The Effect of Plant Cultivar, Growth Media, Harvest Method and Post Harvest Treatment on the Microbiology of Edible Crops," in 42nd International Conference on Environmental Systems, San Diego, California, July 15-19, 2012 (American Institute of Aeronautics and Astronautics). doi:10.2514/ 6.2012-3506

Hummerick, M., Garland, J., Bingham, G., Sychev, V., and Podolsky, I. (2010). "Microbiological Analysis of Lada Vegetable Production Units (VPU) to Define Critical Control Points and Procedures to Ensure the Safety of Space Grown Vegetables," in 40th International Conference on Environmental Systems, Barcelona, Spain, July 11-15, 2010. AIAA 2010-6255. doi:10.2514/6.2010-6255

Humplík, J. F., Lazár, D., Husičková, A., and Spíchal, L. (2015). Automated Phenotyping of Plant Shoots Using Imaging Methods for Analysis of Plant Stress Responses - a Review. Plant Methods 11 (1), 29. doi:10.1186/s13007-015-0072-8

Johnson, C. M., Lucie Poulet, H. B., Bunchek, J., Romeyn, M. W., Spencer, L. E., Dixit, A. R., et al. (2021). Supplemental Food Production with Plants: A Step toward Bioregenerative Life Support. Front. Astron. Space Sci. 8, 198. doi:10.3389/fspas.2021.734343

Jones, S. B., Dani, O., Robert, H., and Markus, T. (2012). Beyond Earth: Designing Root Zone Environments for Reduced Gravity Conditions. Vadose Zone J. 11 (1). doi:10.2136/vzj2011.0081

Khamsen, N., Onwimol, D., Teerakawanich, N., Dechanupaprittha, S., Kanokbannakorn, W., Hongesombut, K., et al. (2016). Rice (Oryza Sativa L.) Seed Sterilization and Germination Enhancement via Atmospheric Hybrid Nonthermal Discharge Plasma. ACS Appl. Mater. Inter. 8 (30), 19268-19275. doi:10.1021/acsami.6b04555

Khodadad, C. L. M., Hummerick, M. E., Spencer, L. E., Dixit, A. R., Richards, J. T., Romeyn, M. W., et al. (2020). Microbiological and Nutritional Analysis of Lettuce Crops Grown on the International Space Station. Front. Plant Sci. 11. doi:10.3389/fpls.2020.00199

Kim, M. S., Chen, Y. R., and Mehl, P. M. (2001). Hyperspectral Reflectance and Fluorescence Imaging System for Food Quality and Safety. Trans. ASAE, 721-729. doi:10.13031/2013.6099

Kim, W., Tengra, F. K., Young, Z., Jasmine, S., Marchand, N., Chan, H. K., et al. (2013). Spaceflight Promotes Biofilm Formation by Pseudomonas Aeruginosa. PLoS One 8 (4), e62437. doi:10.1371/journal.pone.0062437

Kitaya, Y., Kawai, M., Tsuruyama, J., Takahashi, H., Tani, A., Goto, E., et al. (2003). The Effect of Gravity on Surface Temperatures of Plant Leaves. Plant Cel Environ. 26 (4), 497-503. doi:10.1046/j.1365-3040.2003.00980.x

Knief, C. (2014). Analysis of Plant Microbe Interactions in the Era of Next Generation Sequencing Technologies. Front. Plant Sci. 5 (May). doi:10.3389/ fpls.2014.00216

Kruszelnicki, J., Lietz, A. M., and Kushner, M. J. (2019). Atmospheric Pressure Plasma Activation of Water Droplets. J. Phys. D: Appl. Phys. 52 (35), 355207. doi:10.1088/1361-6463/ab25dc

Kuang, A., Popova, A., Xiao, Y., and Musgrave, M. E. (2000). Pollination and Embryo Development in Brassica Rapa L. In Microgravity. Int. J. Plant Sci. 161 (2), 203-211. doi:10.1086/314254

Landry, K. S., Morey, J. M., Bharat, B., Haney, N. M., and Panesar, S. S. (2020). Biofilms-Impacts on Human Health and its Relevance to Space Travel. Microorganisms 8 (7), 998. doi:10.3390/microorganisms 8070998

Levine, H., Weislogel, M., Zhang, Y., Richards, J., Koss, L., Nguyen, A., et al. (2021). "Design and Ground Studies with the Passive Orbital Nutrient Delivery System (PONDS)," in 43rd COSPAR Scientific Assembly, January 28-February 4, 2021.

Lowe, A., Harrison, N., and French, A. P. (2017). Hyperspectral Image Analysis Techniques for the Detection and Classification of the Early Onset of Plant Disease and Stress. Plant Methods 13, 80. doi:10.1186/s13007-017-0233-Z

Mackowiak, C. L., Stutte, G. W., Wheeler, R. M., Ruffe, L. M., and Yorio, N. C. (1999). Tomato and Soybean Production on A Shared Recirculating Hydroponic System. Acta Horticulturae 481 (January), 259-266. doi:10.17660/ActaHortic.1999.481.27

Mahlein, A. K. (2016). Plant Disease Detection by Imaging Sensors - Parallels and Specific Demands for Precision Agriculture and Plant Phenotyping. Plant Dis. 100 (2), 241-251. doi:10.1094/pdis-03-15-0340-fe 
Mahnert, A., Moissl-Eichinger, C., and Berg, G. (2015). Microbiome Interplay: Plants Alter Microbial Abundance and Diversity within the Built Environment. Front. Microbiol. 6. doi:10.3389/fmicb.2015.00887

Martin-Brennan, C., Wheeler, R. M., Sederoff, H. W., and Brown, C. S. (2009). in Bio-Regenerative Life Support Roadmap Workshop.

Massa, G. D., Dufour, N. F., Carver, J. A., Hummerick, M. E., Wheeler, R. M., Morrow, R. C., et al. (2017b). VEG-01: Veggie Hardware Validation Testing on the International Space Station. Open Agric. 2 (1), 33-41. doi:10.1515/opag-2017-0003

Massa, G. D., Santini, J. B., and Mitchell, C. A. (2010). Minimizing Energy Utilization for Growing Strawberries during Long-Duration Space Habitation. Adv. Space Res. 46 (6), 735-743. doi:10.1016/j.asr.2010.02.025

Massa, G. D., Wheeler, R. M., Romeyn, M. W., Hummerick, M. E., Spencer, L. E., Morrow, R. C., et al. (2018). "Preparation for Pick-And-Eat Food Production on the International Space Station: Flight Definition for the VEG-04 and VEG-05 Missions," in 2018 NASA Human Research Program Investigators' Workshop (Galveston, TX). Available at: https://ntrs.nasa.gov/citations/20180000694.

Massa, G. D., Newsham, G., Hummerick, M. E., Morrow, R. C., and Wheeler, R. M. (2017a). Plant Pillow Preparation for the Veggie Plant Growth System on the International Space Station. Gravit. Space Res. 5 (1), 24-34. doi:10.2478/gsr2017-0002

Mickens, M. A., Torralba, M., Robinson, S. A., Spencer, L. E., Romeyn, M. W., Massa, G. D., et al. (2019). Growth of Red Pak Choi under Red and Blue, Supplemented White, and Artificial Sunlight provided by LEDs. Scientia Horticulturae 245 (February), 200-209. doi:10.1016/j.scienta.2018.10.023

Ming, D. W., and Henninger, D. L. (1990). Lunar Base Agriculture: Soils for Plant Growth. Soil Sci. 150 (2), 562. doi:10.1097/00010694-199008000-00012

Mishra, P., Asaari, M. S. M., Herrero-Langreo, A., Lohumi, S., Diezma, B., and Paul, S. (2017). Close Range Hyperspectral Imaging of Plants: A Review. Biosyst. Eng. 164 (December), 49-67. doi:10.1016/j.biosystemseng.2017.09.009

Mitchell, C. A., Dzakovich, M. P., Gomez, C., Lopez, R., Burr, J. F., Hernández, R., et al. (2015). "Light-Emitting Diodes in Horticulture," in Horticultural Reviews (John Wiley \& Sons), Vol. 43, 1-88. doi:10.1002/9781119107781.ch01

Monje, O., Dreschel, T., Nugent, M., Hummerick, M., Spencer, L., Romeyn, M., et al. (2019). "New Frontiers in Food Production beyond LEO," in 49th International Conference on Environmental Systems, Boston, Massachusetts, July 7-11, 2019. Available at: https://ttu-ir.tdl.org/handle/2346/84471.

Monje, O., Nugent, M., Spencer, L. E., Finn, J. R., Kim, M. S., Qin, J., et al. (2021). "Design of a Plant Health Monitoring System for Enhancing Food Safety of Space Crop Production Systems," in 50th International Conference on Environmental Systems. In review.

Morrow, R. C., Wetzel, J., Richter, R., and Crabb, T. (2017). Evolution of SpaceBased Plant Growth Technologies for Hybrid Life Support Systems. Charleston, South Carolina. Available at: https://ttu-ir.tdl.org/handle/2346/73075.

Morrow, R. C., Bula, R. J., Tibbitts, T. W., and Dinauer, W. R. (1994). The AstrocultureTM Flight Experiment Series, Validating Technologies for Growing Plants in Space. Adv. Space Res. 14 (11), 29-37. doi:10.1016/02731177(94)90276-3

Mungin, R., Weislogel, M., Tyler, H., and McQuillen, J. (2019). Omni-Gravity Hydroponics for Space Exploration. Available at: https://ttu-ir.tdl.org/handle/ $2346 / 84457$.

Nagasubramanian, K., Jones, S., Singh, A. K., Sarkar, S., Singh, A., and Ganapathysubramanian, B. (2019). Plant Disease Identification Using Explainable 3D Deep Learning on Hyperspectral Images. Plant Methods 15, 98. doi:10.1186/s13007-019-0479-8

National Research Council (2012). "Division on Engineering and Physical Sciences, Aeronautics and Space Engineering Board, Space Studies Board, and Committee for the Decadal Survey on Biological and Physical Sciences in Space," in Recapturing a Future for Space Exploration: Life and Physical Sciences Research for a New Era (National Academies Press).

Odeh, R., and Guy, C. (2017). Gardening for Therapeutic People-Plant Interactions during Long-Duration Space Missions. Open Agric. 2 (February), 1-13. doi:10.1515/opag-2017-0001

Pecman, A., Kutnjak, D., Gutiérrez-Aguirre, I., Adams, I., Fox, A., Boonham, N., et al. (2017). Next Generation Sequencing for Detection and Discovery of Plant Viruses and Viroids: Comparison of Two Approaches. Front. Microbiol. 8 (October). doi:10.3389/fmicb.2017.01998

Piombo, E., Ahmed, A., Droby, S., Wisniewski, M., Spadaro, D., and Schena, L. (2021). Metagenomics Approaches for the Detection and Surveillance of
Emerging and Recurrent Plant Pathogens. Microorganisms 9 (1), 188. doi:10.3390/microorganisms 9010188

Porterfield, D. M. (2002). The Biophysical Limitations in Physiological Transport and Exchange in Plants Grown in Microgravity. J. Plant Growth Regul. 21 (2), 177-190. doi:10.1007/s003440010054

Poulet, L., Dussap, C. G., and Fontaine, J. P. (2020). Development of a Mechanistic Model of Leaf Surface Gas Exchange Coupling Mass and Energy Balances for LifeSupport Systems Applications. Acta Astronautica 175 (October), 517-530. doi:10.1016/j.actaastro.2020.03.048

Poulet, L., Zeidler, C., Bunchek, J., Zabel, P., Vrakking, V., Schubert, D., et al. (2021). Crew Time in a Space Greenhouse Using Data from Analog Missions and Veggie. Life Sci. Space Res. 31, 101-112. ISSN 2214-5524. doi:10.1016/ j.lssr.2021.08.002

Puligundla, P., Kim, J. W., and Mok, C. (2017a). Effect of Corona Discharge Plasma Jet Treatment on Decontamination and Sprouting of Rapeseed (Brassica Napus L.) Seeds. Food Control 71 (January), 376-382. doi:10.1016/ j.foodcont.2016.07.021

Puligundla, P., Kim, J. W., and Mok, C. (2017b). Effects of Nonthermal Plasma Treatment on Decontamination and Sprouting of Radish (Raphanus Sativus L.) Seeds. Food Bioproc. Techn. 10 (6), 1093-1102. doi:10.1007/s11947-017-1886-3

Ranieri, P., Sponsel, N., Kizer, J., Rojas-Pierce, M., Hernandez, R., Gatiboni, L., et al. (2020). Plasma Agriculture: Review from the Perspective of the Plant and its Ecosystem. Plasma Process. Polym. 18. doi:10.1002/ppap.202000162

Richards, J. T., Edney, S. L., Yorio, N. C., Stutte, G. W., Nathan, C., Wheeler, R. M., et al. (2004). Effects of Lighting Intensity and Supplemental CO2 on Yield of Potential Salad Crops for ISS. SAE Technical Paper 2004-01-2296. Warrendale, PA: SAE International. doi:10.4271/2004-01-2296

Romeyn, M., Spencer, L., Massa, G. D., and Wheeler, R. M. (2019). Crop Readiness Level (CRL): A Scale to Track Progression of Crop Testing for Space. Available at: https://ttu-ir.tdl.org/handle/2346/84592.

Russell, J. F., Klaus, D. M., and Mosher, T. J. (2006). Applying Analysis of International Space Station Crew-Time Utilization to Mission Design. J. Spacecraft Rockets 43 (1), 130-136. doi:10.2514/1.16135

Schuerger, A. C. (1998). Microbial Contamination of Advanced Life Support (Als) Systems Poses A Moderate Threat to the Long-Term Stability of Space-Based Bioregenerative Systems. Life Support Biosph. Sci. 5 (3), 325-337.

Sevanthi, R., Christenson, D., Cummings, E., Nguyen, K., Morse, A., and Andrew Jackson, W. (2014). "Performance of a Full Scale MABR (CoMANDR 2.0) for Pre-treatment of a Habitation Waste Stream Prior to Desalination," in 44th International Conference on Environmental Systems, Tucson, Arizona, July 13-17, 2014. Available at: https://ttu-ir.tdl.org/handle/2346/59656.

Sillankorva, S., and Azeredo, J. (2014). Bacteriophage Attack as an Anti-biofilm Strategy. Methods Mol. Biol. (Clifton, N.J.) 1147, 277-285. doi:10.1007/978-14939-0467-9 20

Stahl-Rommel, S., Jain, M., Nguyen, H. N., Arnold, R. R., Aunon-Chancellor, S. M., Sharp, G. M., et al. (2021). Real-Time Culture-independent Microbial Profiling Onboard the International Space Station Using Nanopore Sequencing. Genes 12 (1), 106. doi:10.3390/genes 12010106

Stern, J. C., Sutter, B., Freissinet, C., Navarro-González, R., McKay, C. P., Archer, P. D., et al. (2015). Evidence for Indigenous Nitrogen in Sedimentary and Aeolian Deposits from the Curiosity Rover Investigations at Gale Crater, Mars. Proc. Natl. Acad. Sci. 112 (14), 4245-4250. doi:10.1073/pnas.1420932112

Strayer, R. F., Finger, B. W., and Alazraki, M. P. (1997). Effects of Bioreactor Retention Time on Aerobic Microbial Decomposition of CELSS Crop Residues. Adv. Space Res. 20 (10), 2023-2028. doi:10.1016/S0273-1177(97)00936-8

Stutte, G., Monje, O., Neil, Y., Edney, S., Newsham, G., Connole, L., et al. (2009). Sustained Salad Crop Production Requirements for Lunar Surface. SAE Int. J. Aerospace 4 (June), 172-178. doi:10.4271/2009-01-2381

Stutte, G., Wheeler, R. M., Morrow, R. C., and Newsham, G. (2011). "Concept for Sustained Plant Production on ISS Using VEGGIE Capillary Mat Rooting System," in 41st International Conference on Environmental Systems, July 16-16, 2020 (American Institute of Aeronautics and Astronautics). doi:10.2514/6.2011-5263

Stutte, G. W., Eraso, I., Anderson, S., and Hickey, R. D. (2006). Bioactivity of Volatile Alcohols on the Germination and Growth of Radish Seedlings. HortScience 41 (1), 108-112. doi:10.21273/HORTSCI.41.1.108

Sychev, V. N., Levinskikh, M. A., Gostimsky, S. A., Bingham, G. E., and Podolsky, I. G. (2007). "Spaceflight Effects on Consecutive Generations of Peas Grown 
Onboard the Russian Segment of the International Space Station. Acta Astronautica 60 (4), 426-432. doi:10.1016/j.actaastro.2006.09.009

Takemura, Y., Umeji, S., Ito, K., Furuya, S., and Furuta, M. (2014). Inactivation Treatment of Bacterial Spores Contaminated Spices by Atmospheric Plasma Jet. Plasma Med. 4 (1-4), 89-100. doi:10.1615/PlasmaMed.2014011969

Thomas, S., Kuska, M. T., Bohnenkamp, D., Brugger, A., Alisaac, E., Wahabzada, M., et al. (2018). Benefits of Hyperspectral Imaging for Plant Disease Detection and Plant protection: a Technical Perspective. J. Plant Dis. Prot. 125, 5-20. doi:10.1007/s41348-017-0124-6

Velez-Justiniano, Y. A., Carter, D., Nur, M., and Angle, G. (2020). "Developing Methods for Biofilm Control in Microgravity for a Water Recovery System," in International Conference on Environmental Systems, July 12-17, 2011. Available at: https://ttu-ir.tdl.org/handle/2346/86332.

Verseux, C., Baqué, M., Lehto, K., De Vera, J., Rothschild, L., and Billi, D. (2016). Sustainable Life Support on Mars - the Potential Roles of Cyanobacteria. Int. J. Astrobiology 15 (1), 65-92. doi:10.1017/S147355041500021X

Volkmann, D., and Tewinkel, M. (1996). Gravisensitivity of Cress Roots: Investigations of Threshold Values under Specific Conditions of Sensor Physiology in Microgravity. Plant Cel Environ. 19 (10), 1195-1202. doi:10.1111/j.1365-3040.1996.tb00435.x

Wamelink, G. W. W., Frissel, J. Y., Krijnen, W. H. J., and Verwoert, M. R. (2019). Crop Growth and Viability of Seeds on Mars and Moon Soil Simulants. Open Agric. 4, 509-516. doi:10.1515/opag-2019-0051

Wheeler, R. (2017). Agriculture for Space: People and Places Paving the Way. Open Agric. 2, 14-32. doi:10.1515/opag-2017-0002

Wheeler, R. M., Mackowiak, C. L., Stutte, G. W., Yorio, N. C., Ruffe, L. M., Sager, J. C., et al. (2008). Crop Productivities and Radiation Use Efficiencies for Bioregenerative Life Support. Adv. Space Res. 41 (5), 706-713. doi:10.1016/j.asr.2007.06.059

Wheeler, R. M., and Martin-Brennan, C. (2000). "Mars Greenhouses: Concept and Challenges," in NASA Tech. Memorandum 208577. Proceedings from a 1999 Workshop.

Wheeler, R. M., Tibbitts, T. W., and Fitzpatrick, A. H. (1991). Carbon Dioxide Effects on Potato Growth under Different Photoperiods and Irradiance. Crop Sci. 31 (5), cropsci1991. doi:10.2135/cropsci1991.0011183X003100050026x

Wheeler, R. M., Peterson, B. V., and Stutte, G. W. (2004). Ethylene Production throughout Growth and Development of Plants. HortScience 39 (7), 1541-1545. doi:10.21273/HORTSCI.39.7.1541

Xiao, Z., Codling, E. E., Luo, Y., Nou, Xi., Lester, G. E., and Wang, Q. (2016). Microgreens of Brassicaceae: Mineral Composition and Content of 30 Varieties. J. Food Compost. Anal. 49 (June), 87-93. doi:10.1016/j.jfca.2016.04.006

Xiao, Z., Lester, G. E., Luo, Y., and Wang, Q. (2012). Assessment of Vitamin and Carotenoid Concentrations of Emerging Food Products: Edible Microgreens. J. Agric. Food Chem. 60 (31), 7644-7651. doi:10.1021/jf300459b

Yamaguchi, N., Roberts, M., Castro, S., Oubre, C., Makimura, K., Leys, N., et al. (2014). Microbial Monitoring of Crewed Habitats in Space-Current Status and Future Perspectives. Microbes and Environments 29 (3), 250-260. doi:10.1264/ jsme2.me14031
Zabel, P., Bamsey, M., Zeidler, C., Vincent, V., Schubert, D., and Oliver, R. (2017) "Future Exploration Greenhouse Design of the EDEN ISS Project," in 47th International Conference on Environmental Systems, Charleston, South Carolina. Available at: https://ttu-ir.tdl.org/ttu-ir/handle/2346/72919.

Zabel, P., Bamsey, M., Schubert, D., and Tajmar, M. (2016). Review and Analysis of over 40 Years of Space Plant Growth Systems. Life Sci. Space Res. 10 (August), 1-16. doi:10.1016/j.lssr.2016.06.004

Zahoranová, A., Hoppanová, L., Šimončicová, J., Tučeková, Z., Medvecká, V., Hudecová, D., et al. (2018). Effect of Cold Atmospheric Pressure Plasma on Maize Seeds: Enhancement of Seedlings Growth and Surface Microorganisms Inactivation. Plasma Chem. Plasma Process. 38 (5), 969-988. doi:10.1007/ s11090-018-9913-3

Zeidler, C., Vincent, V., Bamsey, M., Poulet, L., Paul, Z., Schubert, D., et al. (2017). Greenhouse Module for Space System: A Lunar Greenhouse Design. Open Agric. 2 (1), 116-132. doi:10.1515/opag-2017-0011

Zeidler, C., Woeckner, G., Johannes, S., Vincent, V., Paul, Z., Dorn, M., et al. (2021). Crew Time and Workload in the EDEN ISS Greenhouse in Antarctica. Life Sci. Space Res. (Amst). 31, 131-149. ISSN 2214-5524. doi:10.1016/j.lssr.2021.06.003

Zeidler, C., Zabel, P., Vrakking, V., Dorn, M., Bamsey, M., Schubert, D., et al. (2019). The Plant Health Monitoring System of the EDEN ISS Space Greenhouse in Antarctica during the 2018 Experiment Phase. Front. Plant Sci. 10, 1457. doi:10.3389/fpls.2019.01457

Conflict of Interest: Author SS-R is employed by JES Tech; author Y-AVJ is employed by Aerodyne Industries LLC; authors, OM, MH, CK, and LS, are employed by Amentum.

The remaining authors declare that the research was conducted in the absence of any commercial or financial relationships that could be construed as a potential conflict of interest.

Publisher's Note: All claims expressed in this article are solely those of the authors and do not necessarily represent those of their affiliated organizations, or those of the publisher, the editors and the reviewers. Any product that may be evaluated in this article, or claim that may be made by its manufacturer, is not guaranteed or endorsed by the publisher.

Copyright (๑) 2022 Poulet, Engeling, Hatch, Stahl-Rommel, Velez Justiniano, CastroWallace, Bunchek, Monje, Hummerick, Khodadad, Spencer, Pechous, Johnson, Fritsche, Massa, Romeyn, O'Rourke and Wheeler. This is an open-access article distributed under the terms of the Creative Commons Attribution License (CC BY). The use, distribution or reproduction in other forums is permitted, provided the original author(s) and the copyright owner(s) are credited and that the original publication in this journal is cited, in accordance with accepted academic practice. No use, distribution or reproduction is permitted which does not comply with these terms. 